Original Research Paper

\title{
System Dynamics Analysis of the Determinants of the Malaysian Palm Oil Price
}

\author{
${ }^{1}$ Sahra Mohammadi, ${ }^{1}$ Fatimah Mohamed Arshad, ${ }^{2}$ Bilash Kanti Bala and ${ }^{2}$ Abdulla Ibragimov \\ ${ }^{I}$ Faculty of Economics and Management, Universiti Putra Malaysia, Selangor, Malaysia \\ ${ }^{2}$ Institute of Agriculture and Food Policy Studies, Universiti Putra Malaysia, Selangor Malaysia
}

Article history

Received: 09-03-2015

Revised: $19-05-2015$

Accepted: 21-06-2015

Corresponding Author:

Sahra Mohammadi

Faculty of Economics and

Management, Universiti Putra

Malaysia, Selangor, Malaysia

Email: sahara.mhd@gmail.com

\begin{abstract}
This paper investigates the major determinants of the Malaysian palm oil price using a system dynamics approach. System dynamics methodology is very relevant for examining the feedback relationships, non-linearity and delays exist in palm oil market. It helps understand the palm oil market structure and the resultant behavior and performance particularly On crude Palm Oil (CPO) price. The simulation results indicate that the Malaysian CPO price is significantly affected by the local CPO production as well as the world CPO and soybean oil prices. It is also found that CPO price is less sensitive to biodiesel production, as biodiesel currently accounts for small portion of total CPO demand in Malaysia.
\end{abstract}

Keywords: System Dynamics, Commodity Systems, Palm Oil, Malaysia

\section{Introduction}

The price of Malaysian palm oil demonstrates significant variation from time to time. Like other agricultural commodities, variation in palm oil price increases due to three important market fundamentals. First, agricultural output varies from period to period because of natural shocks such as weather. Second, supply and demand elasticity are relatively small with respect to price, especially in the short run. Third, there is a high delay in supply of agricultural commodities as their production take considerable time and supply cannot respond to price changes in short term (FAO, 2011). Variations in price create uncertainty which increases risks for producers, traders, consumers and governments and may lead to sub-optimal decisions.

Malaysian Crude Palm Oil (CPO) price has increased by $65 \%$ during the last two decades from RM $829 / \mathrm{mt}$ in 1982 to RM 2,383/mt in 2014 (MPOB, 2012). Looking at the long term behavior, it can be seen that higher price variation in palm oil has occurred during Asian financial crisis in 1997 and global food crisis in 2008 where palm oil price increased by 42 and $35 \%$, respectively. The observed behavior shows that palm oil price had higher degree of variation during the $2000 \mathrm{~s}$ than previous two decades. Figure 1 shows the historical behavior of local and the world CPO productions and prices as well as the World soybean oil (SBO) price for the last three decades.

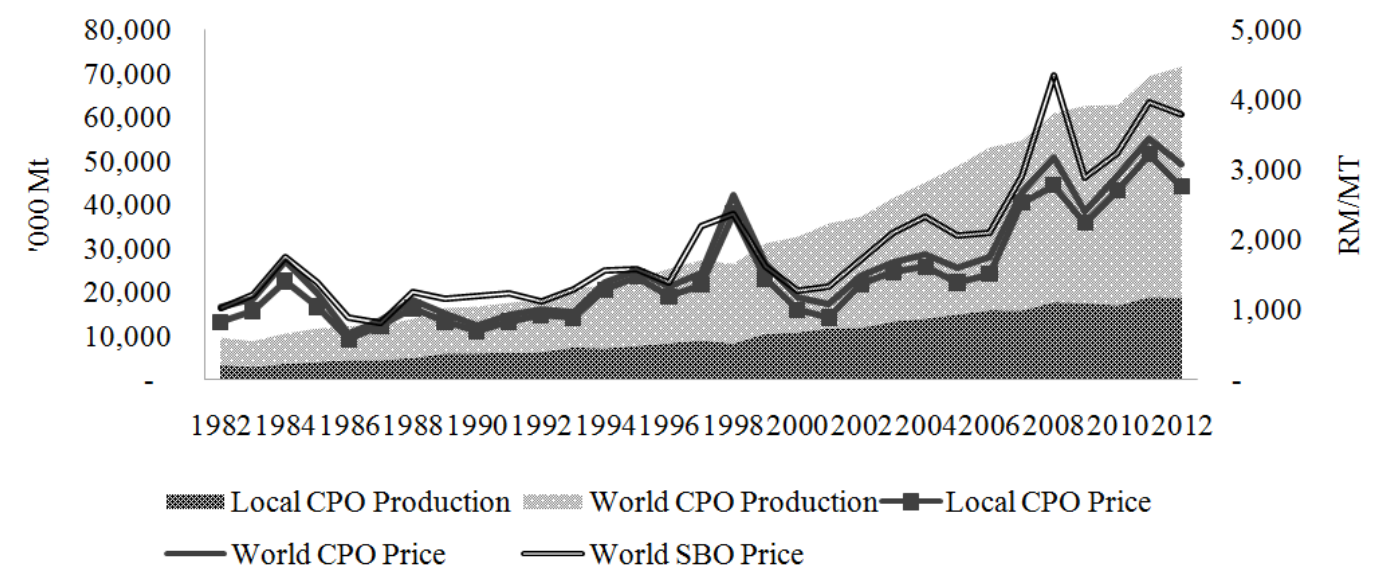

Fig. 1. Local and the world CPO productions, prices and the world soybean oil price, 1982-2012 
This paper investigates the major determinants of Malaysian palm oil price. More specifically, this paper examines the palm oil market structure and the resultant behavior and performance particularly on CPO price. It simulates the impact changes in CPO production, the world CPO and soybean oil prices and biodiesel production on the Malaysian CPO price. Understanding the price behavior helps decision makers to be aware of the possible future trends and turns and to make informed decisions.

\section{Literature Review}

Meadows (1979) stated that the most fundamental cause of failure to address commodity prices is our inability to comprehend all aspects of the dynamic interaction exist in a market. As mentioned earlier, there is a high delay in supply of agricultural commodities including palm oil and thus, system dynamics is a relevant methodology as it allows us capture the delays exist in the palm oil market. The analysis of dynamic environments requires us to capture non-linear relationships between components, which is difficult to enhance with traditional econometric techniques (Kumar and Nigmatullin, 2012; Fuchs, 2006). System dynamics is a powerful tool for policy analysis because it enables one to simulate different patterns of system behaviors in a computer platform when there are changes in the internal structure or parameter values. Modelling and simulation provide conceptual diagrams to generate immediate feedbacks from performance of all components contributing in a system (Meyers, 2011).

Currently, there is no evidence showing that system dynamics was used to examine the long-term dynamics involved in the palm oil price. However, there are studies that developed system dynamics models for analyzing other aspects of palm oil industry. For example, Hidayatno et al. (2011) examined the impact of Indonesian government policy on palm feedstock and biodiesel production using system dynamics; Franco et al. (2009) adapted system dynamics to investigate the impact of Colombian government policy on palm feedstock and biodiesel production; and Yahaya et al. (2006) studied the relationship between palm oil, petroleum and biodiesel production using the same methodology. The present paper aims to utilize system dynamics to study the market structure and price behavior of palm oil in Malaysia.

Moreover, there are studies carried out to understand Malaysian palm oil market using other approaches rather than system dynamics. Basri et al. (2007) applied econometric model on Malaysian palm oil industry for fourteen behavioral equations. The result of palm oil price model showed that the Malaysian price is effected by $\mathrm{CPO}$ export, world CPO price, refinery utilization rate and crisis in economy. Ab Rahman et al., (2007) examined domestic prices of selected palm oil products and the major causative factors of price variation. The study used various models including the Autoregressive Conditional Heteroskedasticity (ARCH), Generalized ARCH (GARCH) and Vector Error Correction Model (VECM). The result showed that price volatility is statistically significant with CPO indicating the higher volatility among other palm oil products. Abdullah et al. (2007) identified the factors effecting the palm oil price in Malaysia. The result indicated that the long-term factors include stock coverage of oil and fats, palm oil export, soybean oil price as the main substitute to palm oil, world palm oil supply and demand as well as palm oil production. The short-term factors include market sentiments such as trade barriers and price of crude oil. Basri et al. (2007) also studied the palm oil price. The study showed the importance of well-managed stocks of palm oil on the price of this commodity. It also stressed the impact of soybean oil and crude oil prices on CPO price. The present study, however, adapts system dynamics method to study the dynamics involved in the palm oil price which is difficult to enhance with traditional econometric techniques.

\section{Methodology}

System dynamics methodology is very relevant for examining the feedback relationships between variables, non-linearity and delays that exist in palm oil market. Modeling and simulation helps understand the impact of the market structure and hence, the behavior of palm oil price both in the short run and long run. A short-run perspective gives opportunities to the industry players to make short term decisions such as taking position in the futures market (hedging) and fund management. In addition, a long-run perspective allows time for them to make long-term decisions such as investment on land capital as well as inventory management.

System dynamics method is based on feedback processes which are responsible for the changes occurring throughout the time. It investigates within a system to identify internal causes of a problem. It creates an endogenous point of view that calls for interconnected loops of information feedback and circular causality to capture behaviors within system boundaries (Meyers, 2011). Different processes for model development have been put forward in the system dynamics literature (Martinez-Moyano and Richardson, 2013; Sterman, 2000; Richardson and Pugh, 1981). Generally, the system dynamics modeling process could be summarized with the following phases: 
- Problem Articulation: Identifying and articulating the issue to be addressed

- Model Conceptualization: Developing a causal theory about the issue

- Model Formulation: Formulating a system dynamics simulation model of the causal theory

- Model Validation: Testing the model to assess whether it is fit for the purpose

- Model Use: Using the model to design and evaluate structural policies to address the issue

\section{Modeling Process of the Malaysian Palm Oil Market}

This paper follows the same process in system dynamics modeling as mentioned above. The following paragraphs illustrate the modeling process of the Malaysian palm oil price.

\section{Problem Articulation}

The palm oil industry has made a significant contribution to the Malaysian agricultural sector and has become an important driver in Malaysian economy. In 2011, palm oil accounted for $6 \%$ of the GDP and $61.8 \%$ of the export value in Malaysia. The industry provides employment to approximately 2.2 $\mathrm{mn}$ people, which is the largest in the country. Moreover, oil palm cultivation has become an effective means to address rural poverty.

Nevertheless, the price of palm oil exhibits variations which can produce uncertainty to the industry players. Understanding the dynamic relationship between the important aspects of the commodity system may provide clues as to possible strategies to address price variation. Although it is unrealistic to influence the magnitude of exogenous disturbance, we can reduce their impact by understanding the commodity system (Meadows, 1979). The palm oil industry has significant economic advantages and it is vital to identify factors contributing to its price behavior.

\section{Model Conceptualization}

The most used diagrams in system dynamics are Casual Loop Diagram (CLD) for model conceptualization and Stock and Flow (S\&F) diagram for quantitative analysis. Causal loop diagrams, or the qualitative structures, allow to map a system by accumulating casual relationships between variables (Pruyt, 2013). The CLD of Malaysian palm oil market is presented in Fig. 2. As shown, the model consists of three balancing loops and five reinforcing loops. The balancing loops include production loop (B1), land availability loop (B2) and export demand loop (B3). The reinforcing loops include palm age profile loop (R1), biodiesel demand loop (R2), world supply loop (R3), world demand loop
(R4) and world price loop (R5). Table 1 presents the sequence of balancing and reinforcing loops in the CLD of palm oil market in Malaysia.

\section{Model Formulation}

In system dynamics modelling process CLDs are further converted into Stock and Flow (S\&F) diagrams using a simulation software, Vensim in this study. S\&F diagrams, or quantitative structures, accumulate materials as well as information. They mainly consist of stock variables, flow variables, auxiliary variables, parameters and equations. Stocks are the inventories and flows stand for the rate of change in stocks. Decisions and information alter the rate of change in flows which consequently alter the stocks. The S\&F diagram of Malaysian palm oil market is presented in Fig. 3 and the formulation of key variables are explained in the following paragraphs.

The oil palm structure comprises growth stages of palm oil trees from immature trees to young, mature and old trees that are taken as stock in the production cycle. The trigger to initiate new plantation is the effect of profitability on new plantation which affects the desired planted area. The palm productivity begins when the trees pass immature age and it reaches the peak during mature age and then it gradually decreases during old ages. Total mature crop multiplied by FFB productivity per crop area forms the total FFB. The $\mathrm{CPO}$ production is obtained by multiplying the Oil Extraction Rate (OER) by FFB production.

The palm oil price is significantly affected by inventory coverage in the sense that the higher the inventory coverage the lower is the price. Relative inventory coverage is a function of inventory coverage and desired inventory coverage. Desired inventory coverage is the number of months the market desires to maintain the inventory. In case of commodity products, desired inventory coverage is usually estimated to be about one year. Moreover, the expected profitability is calculated from CPO price and expected production cost using SMOOTH function. Sterman (2000) mentioned that "Expectations about prices are strongly conditioned by past prices and can be modeled by some form of adaptive expectations, such as exponential smoothing".

The CPO inventory increases by inflows of supply and it decreases through the outflows of demand. The supply side consists of two inflows including CPO production and import. The demand side consists of three outflows including CPO for Processed Palm Oil (PPO), CPO for export and CPO for biodiesel production. The production of PPO demands the largest proportion of available CPO in Malaysia. That is, about $80 \%$ of the available CPO is further processed for local consumption and PPO export. 


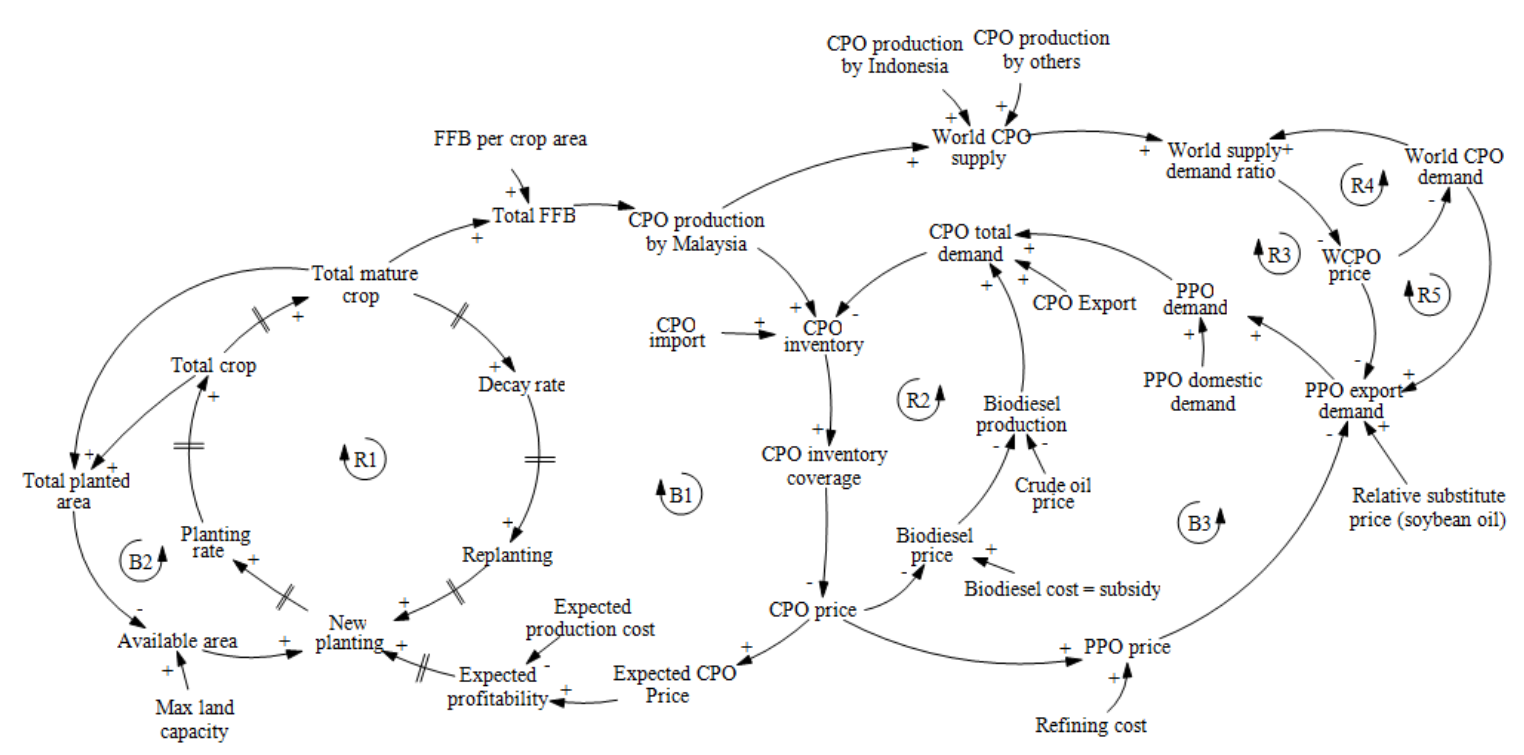

Fig. 2. CLD of the Malaysian palm oil market

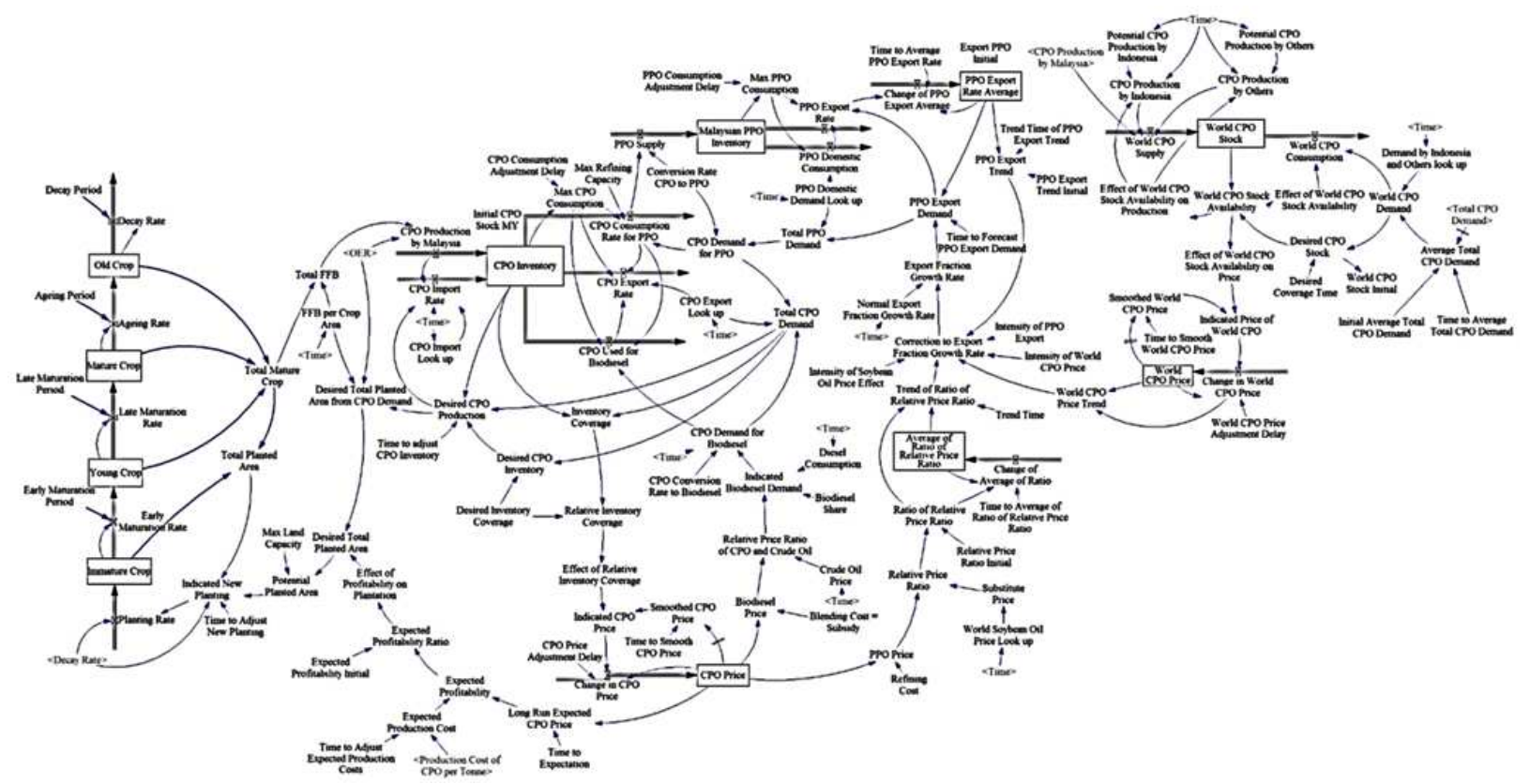

Fig. 3. S\&F Diagram of the Malaysian palm oil market

As the largest demand of Malaysian crude palm oil, PPO export has a significant effect on the total demand for Malaysian CPO and its price. The export of PPO is affected by three important factors namely PPO price, world CPO price and soybean oil price as the substitute vegetable oil for palm oil. Among all vegetable oils, soybean oil is the main substitute for palm oil (Applanaidu et al., 2010) with high correlation index of 0.82 (Abdullah et al., 2007). The price of PPO is the sum of CPO price and PPO refining cost which is estimated at RM 89/mt of palm oil (Basiron and Simeh, 2005).
The production of biodiesel in Malaysia began in 2006 when the price of crude oil increased dramatically from USD 28.72/barrel in 2004 to about USD 70/barrel in 2006. Meanwhile, Malaysia's price of CPO decreased from RM 1,610/mt to RM 1,511/mt during the same period. Currently, about $2 \%$ of CPO is used in the production of biodiesel. Malaysian government expects an increase in biodiesel production as a result of the introduction of blend 10 (B10), which refers to $10 \%$ palm methyl ester and $90 \%$ petroleum based diesel. 
Table 1. Sequence of balancing and reinforcing loops in Malaysian palm oil model

\begin{tabular}{|c|c|}
\hline Loop & Causal links \\
\hline \multicolumn{2}{|l|}{ Balancing loops } \\
\hline B1: Production & $\begin{array}{l}\text { CPO Price-Expected CPO Price-Expected Profitability-New Planting-Planting Rate-Total Crop-Total } \\
\text { Mature Crop-Total FFB-CPO Production-CPO Inventory-CPO Inventory Coverage-CPO Price. }\end{array}$ \\
\hline B2: Land availability & $\begin{array}{l}\text { New Planting-Planting Rate-Total Crop-Total Mature Crop-Total Planted Area-Available Area-New } \\
\text { Planting. }\end{array}$ \\
\hline B3: Export demand & $\begin{array}{l}\text { CPO Price-PPO Price-PPO Export Demand-PPO Demand-CPO Total Demand-CPO Inventory-CPO } \\
\text { Inventory Coverage-CPO Price. }\end{array}$ \\
\hline \multicolumn{2}{|r|}{ 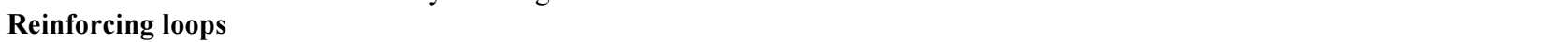 } \\
\hline R1: Palm age profile & New Planting-Planting Rate-Total Crop-Total Mature Crop-Decay Rate-Replanting-New Planting. \\
\hline R2: Biodiesel demand & $\begin{array}{l}\text { CPO Price-Biodiesel Price-Biodiesel Production-CPO Total Demand-CPO Inventory-CPO Inventory } \\
\text { Coverage-CPO Price. }\end{array}$ \\
\hline R3: World supply & $\begin{array}{l}\text { World CPO Supply-World Supply Demand Ratio-World CPO Price-PPO Export Demand-PPO } \\
\text { Demand-CPO Total Demand-CPO Inventory-CPO Inventory Coverage-CPO Price-Expected CPO Price } \\
\text {-Expected Profitability-New Planting-Planting Rate-Total Crop-Total Mature Crop-Total FFB-CPO } \\
\text { Production-World CPO Supply. }\end{array}$ \\
\hline R4: World demand & World CPO Price-World CPO Demand-World Supply Demand Ration-World CPO Price. \\
\hline R5: World price & $\begin{array}{l}\text { World CPO Price-WCPO Demand-MYPPO Export Demand-MYPPO Demand-MYCPO Total } \\
\text { Demand-MYCPO Inventory-MYCPO Inventory Coverage-MYCPO Price-Expected MYCPO Price } \\
\text {-Expected Profitability-New Planting-Planting Rate-Total Crop-Total Mature Crop-Total FFB } \\
\text {-MYCPO Production-WCPO Supply-World Supply Demand Ration-WCPO Price. }\end{array}$ \\
\hline
\end{tabular}

Table 2. Error analysis of key variables in Malaysian palm oil model, 1982-2012

\begin{tabular}{lclll}
\hline & & \multicolumn{3}{l}{ Inequality statistics } \\
Variable & $\begin{array}{l}\text { RMSPE } \\
\text { (\%) }\end{array}$ & $\mathrm{U}^{\mathrm{M}}$ & $\mathrm{U}^{\mathrm{S}}$ & $\mathrm{U}^{\mathrm{C}}$ \\
\hline Total Mature Crop & 1 & 0 & 0.20 & 0.80 \\
Total Planted Area & 2 & 0 & 0.25 & 0.75 \\
Total CPO Demand & 15 & 0 & 0.79 & 0.21 \\
CPO Production & 23 & 0 & 0.00 & 1.00 \\
CPO Price & 120 & 0 & 0.18 & 0.82 \\
Biodiesel Production & 121 & 0 & 0.33 & 0.87 \\
\hline
\end{tabular}

The world CPO production consists of CPO production by Malaysia, Indonesia and other producing countries. The CPO production by Indonesia and other producing countries are taken as exogenous variables. The world CPO consumption is estimated using the effect of CPO stock availability and CPO demand.

\section{Model Validation and Results}

As the first step in model validation, it is useful to compare the simulation results with the historical data. The simulation results of Malaysian palm oil model produce similar behavior to the observed data. The results for the period of 1982-2012 of three key variables including CPO production, total CPO demand and CPO price are presented in Fig. 4-6.

Moreover, statistical tests such as Root Mean Square Percent Error (RMSPE) and the Theil's inequality test are used to validate the simulation results (Sterman, 1984). The statistical tests for six selected variables are presented in Table 2. The zero value of $\mathrm{U}^{\mathrm{M}}$ for all variables indicates that there is no systematic difference between the model and reality, indicating that the model works in right directions. The RMSPE for four variables including total mature crop $(1 \%)$, total planted area
(2\%), total CPO demand (15\%) and CPO production $(23 \%)$ is small. These four variables produced close behaviors to that of historical data. The RMSPE for CPO price $(120 \%)$ and biodiesel production $(121 \%)$ is larger. But the model is not developed for point-by-point prediction, rather it is developed to study the system behavior and to have some understanding about market structure. Therefore, even though the point-by-point match is poor for the two variables, the model captures the sharp increases in both simulation.

\section{Model Use and Scenario Analysis}

The palm oil market model is used to examine the expected behavior of the Malaysian CPO price under four different scenarios. Under the first scenario, we assume an increase of $10 \%$ in the Malaysian CPO production. Under the second scenario, we assumed an increase of $10 \%$ in the world CPO production. Under the third scenario, we assume an increase of $10 \%$ in the world soybean oil price and lastly, under the forth scenario we introduce a blend of $10 \%$ of biodiesel production into the system.

The impact analysis of the four scenarios is summarized in Fig. 7. The simulation results show that, under the business as usual scenario, the price of Malaysian palm oil is expected to increase by about $52 \%$ over the next fifteen years from RM 2,383/mt in 2014 to RM 5,059/mt in 2030. Under the first scenario, the CPO price decreases to $\mathrm{RM} 4,625 / \mathrm{mt}$, suggesting a reduction of $9 \%$. Under the second scenario, the CPO price decreases to RM 3,929/mt, indicating a reduction of $18 \%$. Under the third scenario, the CPO price raises to RM 5,515/mt, suggesting an increase of $8 \%$ and under the fourth scenario, the CPO price increases to RM $5,101 / \mathrm{mt}$, indicating a change of $1 \%$. 


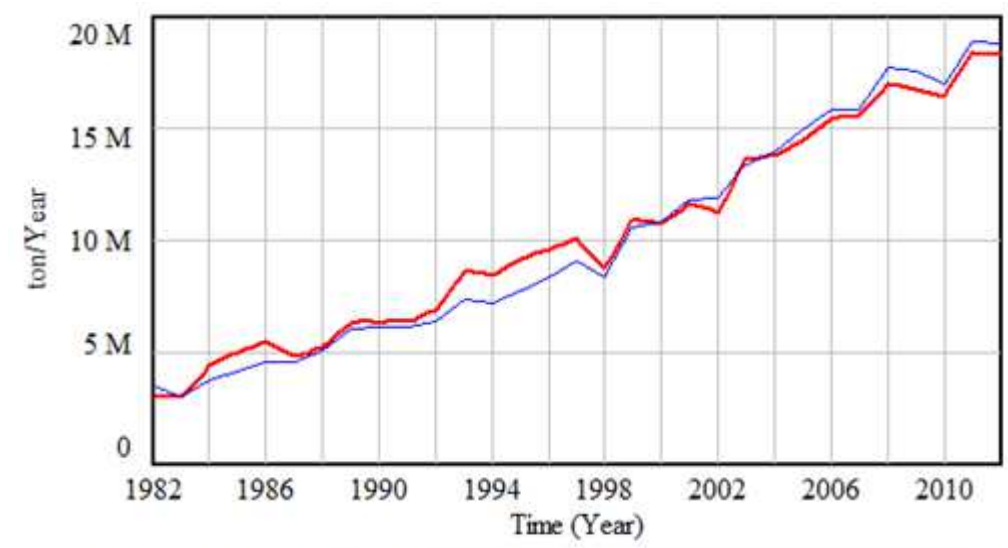

CPO Production : Actual

CPO Production : Simulation

Fig. 4. Simulation result for CPO production

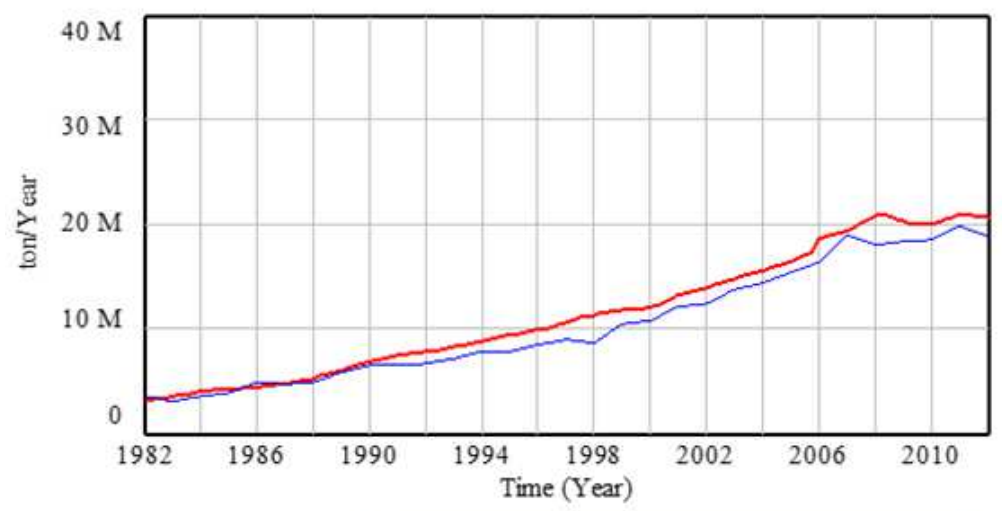

Total CPO Demand : Actual

Total CPO Demand : Simulation

Fig 5. Simulation result for total CPO demand

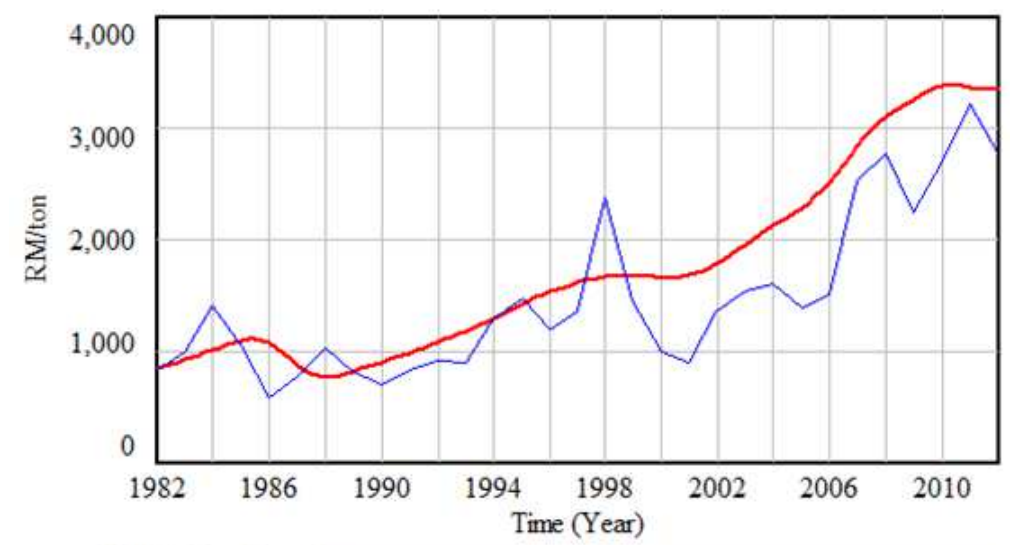

CPO Price : Actual

CPO Price : Simulation

Fig. 6. Simulation result for Malaysian CPO price 


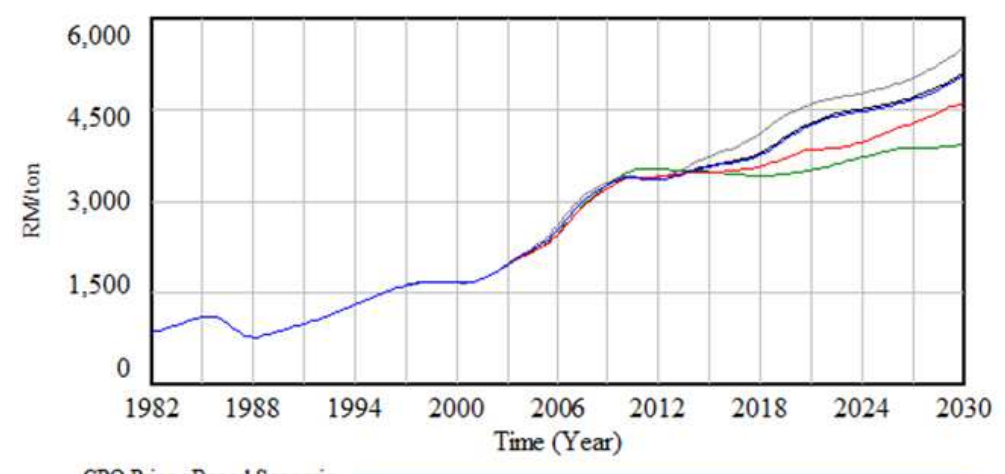

CPO Price : Based Scenario

CPO Price : Scenario I

CPO Price : Scenario II

CPO Price : Scenario III

CPO Price : Scenario IV

Fig. 7. Simulation of CPO price under four scenarios

\section{Discussion}

The simulation results indicate that the CPO price is significantly affected by the Malaysian CPO production as well as the world CPO and soybean oil prices. The CPO price is less sensitive to biodiesel production, as biodiesel currently accounts for only $2 \%$ of total CPO demand in Malaysia. The world CPO price is significantly affected by the Indonesian CPO production which is the world largest producers and major competitor to Malaysia. The expansion of oil palm plantations in Indonesia leads to lower world CPO price which depresses Malaysian local CPO price. In addition, soybean oil is the main substitute vegetable oil of palm oil. Therefore, when the price of soybean oil increases relative to the price of palm oil, the demand for palm oil products increases resulting in an increase of the CPO price. Hence, to minimize the negative impact of shock or large price variation, there is a need to monitor these variables closely and make informed forecast of the likely future trends of the $\mathrm{CPO}$ price.

Based on the understanding of the relationships of these variables, the industry should be able to address price variability better. In the short term, the industry should intensify the usage of risk management tools such as hedging in the futures market and efficient inventory management (Ab Rahman et al., 2012; Rosalan, 1998). Taking the right position in the futures market allows the industry to hedge their CPO inventory from the vagaries of an extreme price change. Taking a position in the futures market requires some forecasts of the $\mathrm{CPO}$ price in the future. Similarly, a proper understanding of the market fundamentals enable the industry to manage their inventory better. An informed price forecast allows the industry to manage their inventory to avoid over or under accumulation of CPO stocks. The long term strategies include internalizing the price instability through firstly, improvements in productivity, efficiency and sustainability in the CPO production sector.
Secondly, to embark further on high value added activities to ensure adequate profits to absorb shocks and variation in the market besides improving overall competitiveness of the industry.

\section{Conclusion}

Price variation is a norm in any commodity market. While price variation is inevitable, the industry may minimize the impact of significant or shocks into the system by understanding the structure and resultant behavior of the market and make informed decisions of the possible future trends of the CPO price. This paper indicates that an increase in the production in both local as well as the international market (which is largely from the Indonesian production), will lead to a reduction in the $\mathrm{CPO}$ price. However, an increase in the soybean price will push the CPO price further as demand for CPO increases.

These findings imply that the palm oil industry must keep track and monitor closely the development of these variables over time and make some intelligent forecast of their likely future trends and implications to the CPO price. Moreover, the Malaysian palm oil industry must develop further value-added products in order to internalize the price changes and to make palm oil ventures economically viable regardless of price changes. The industry should also intensify the usage of risk management tools such as hedging in the futures market and efficient inventory management which require further studies.

\section{Future Study}

This study developed a system dynamics model for Malaysian palm oil market. The model takes into account the key variables that can generate the expected behaviors. However, the boundary of the model can be expanded wider to obtain more accurate results. Some variables such as CPO export and CPO production by Indonesia 
and other producing countries are used as exogenous variables for simplification. These variables can be endogenously integrated with the model. Moreover, future researchers are encouraged to develop a palm oil model for Indonesia to obtain better understanding of market structure of palm oil in the global market.

\section{Acknowledgement}

The authors would like to thank Assoc. Professor Muhammad Tasrif from Bandung Institute of Technology for his expertise and excellent assistance with regards to the methodology of this study.

\section{Author's Contributions}

This study is a result of the full collaboration of all the authors.

Sahra Mohammadi: As performed the experiments, analyzed the data and gave the conclusions, discussed the results, implications and commented on the manuscript at all stages.

Fatimah Mohamed Arshad: As the advisor, she designed the research plan and organized the study.

Bilash Kanti Bala: The contributed in development of the conceptual framework and the stock and flow diagram.

Abdulla Ibragimov: The author carried out the validation and statistical tests of the developed mode.

\section{Ethics}

This article is original and contains unpublished material. The corresponding author confirms that no ethical issues involved.

\section{Reference}

Ab Rahman, A.K., F.M. Shariff, R. Abdullah and N.H. Sharif, 2007. Price volatility spill over in the Malaysian palm oil industry. Oil Palm Industry Economic J., 7: 24-32.

Ab Rahman, N.M.N., A.S. Nawi and Y.H.N.M. Naziman, 2012. The price discovery of the Malaysian crude palm oil futures markets. J. Applied Finance Bank., 2: 25-47.

Abdullah, R., R. Abas and K. Ayatollah, 2007. Impact of palm oil-based biodiesel demand on palm oil price. Oil Palm Industry Economic J., 7: 19-27.

Applanaidu, S.D., M.A. Fatimah, M.N. Shamsudin and Z. Yusop, 2010. The impact of biodiesel demand on the Malaysian palm oil market: A combination of econometric and system dynamics approach. Proceedings of the International Conference on Business and Economic Research, Mar. 15-16, Kuching, Sarawak, pp: 1-16.

Basiron, Y. and M.A. Simeh, 2005. Vision 2020-the palm oil phenomenon. Palm Oil Industry Economic J., 5: 1-10.
Basri, A.T., M.F.M. Jani, M.N. Mamat and R. Zakaria, 2007. Impact assessment of liberalizing trade on Malaysian crude palm oil. Oil Palm Industry Economic J., 7: 9-17.

FAO, 2011. Price volatility in food and agricultural markets: Policy responses. FAO.

Franco, C.J., M.C. Ochoa and A.M. Florez, 2009. System dynamics approach to biofuels in Colombia. Proceedings of the 27th International Conference of the System Dynamics Society, Jul. 26-30, Albuquerque, New Mexico, USA, pp: 1-171.

Fuchs, H.U., 2006. System dynamics Modeling in science and engineering. Proceedings of the System Dynamics Conference, Dec. 8-10, University of Puerto Rico, pp: 1-21.

Hidayatno, A., A. Sutrisno, Y.M. Zagloel and W.W. Purwanto, 2011. System dynamics sustainability model of palm-oil based biodiesel production chain in Indonesia. Int. J. Eng. Technol., 11: 1-6.

Kumar, S. and A. Nigmatullin, 2012. A system dynamics analysis of food supply chains-Case Study with Non-perishable products. Simulation Modelling Practice Theory, 19: 2151-2168. DOI: 1016/j.simpat.2011.06.006

Martinez-Moyano. I.J. and G.P. Richardson, 2013. Best practices in system dynamics Modeling. Syst. Dynamics Rev., 29: 102-123. DOI: 10.1002/sdr.1495

Meadows, D.H., 1979. The Unavoidable A Priori. In: Elements of the System Dynamics Method, Randers, J. (Ed.), Cambridge University Press, Cambridge, ISBN-10: 9780262180924, pp: 161-240.

Meyers, R.A., 2011. Complex Systems in Finance and Econometrics. 1st Edn., New York, Springer, ISBN10: 1441977007. pp: 406.

MPOB, 2012. Malaysian palm oil statistics. Malaysian Palm Oil Board.

Pruyt, E., 2013. Small System dynamics models for big issues: Triple jump towards real-world complexity. TU Delft, Delft.

Richardson, G.P. and A.L. Pugh, 1981. Introduction to System Dynamics Modeling with Dynamo. 1st Edn., Pegasus Communications, ISBN-10: 1883823439, pp: 424.

Rosalan, A., 1998. A study on the use of crude palm oil futures as an effective hedging tool for the Malaysian palm oil producers and refiners. AAM J., 3: 34-44.

Sterman, J.D., 1984. Appropriate summary statistics for evaluating the historical fit of system dynamics models. Dynamica, 10: 51-66.

Sterman, J.D., 2000. Business Dynamics: Systems Thinking and Modeling for a Complex World. 1st Edn., Irwin/McGraw-Hill, Boston, ISBN-10: 9780072311358 , pp: 982.

Yahaya, J., A. Sabri and S.W. Kennedy, 2006. Impacts of biodiesel development on the palm oil industry. Malaysian J. Economic. Studies, 43: 113-140. 